\title{
Orientação profissional no ensino médio: revisão de estudos da psicologia brasileira
}

\author{
Professional orientation in middle school: review of \\ studies of brazilian psychology
}

\author{
Helenizia Santos Sobral', Sheyla Christine Santos Fernandes² \\ Autora para correspondência. Instituto de Psicologia, Universidade Federal de Alagoas. Maceió, Alagoas, Brasil. \\ ORCID: 0000-0001-6035-1863. helensobral@hotmail.com \\ ${ }^{2}$ Instituto de Psicologia, Universidade Federal de Alagoas. Maceió, Alagoas, Brasil. sheyla.fernandes@ip.ufal.br
}

\begin{abstract}
Resumo | Tendo como temática a orientação profissional (OP) no ensino médio, elaboramos este artigo com o objetivo de realizar uma revisão sistemática sobre os estudos da psicologia brasileira acerca do referido tema. Para isso, utilizamos cinco bases de dados: LILACS (Literatura Latino-Americana e do Caribe em Ciências da Saúde), Index Psi, SciELO (Scientific Eletronic Library Online), PePSIC e PsycINFO. Ao término da análise, restaram-nos 29 artigos, sendo 04 artigos teóricos e 25 artigos empíricos. As bases teóricas mais utilizadas foram a psicologia positiva e as teorias sociocognitiva e comunitária. Nos artigos empíricos, verificamos que a temática mais frequente foi - uso de escalas, que visam a mensurar a relação dos fatores por elas avaliados e a OP. Como exemplo dessas escalas podemos citar: Escala de Maturidade para Escolha Profissional- EMEP; Escala de Aconselhamento Profissional -EAP; e Escala de Atribuição e Eficácia para Atividades Ocupacionais - EAAOC. Os periódicos científicos que mais publicaram trabalhos sobre essa temática foram aqueles nos quais a OP é tema central de suas publicações. Ficou constatado que nos últimos anos as publicações envolvendo o tema tem diminuído consideravelmente se comparadas à década passada.
\end{abstract}

Palavras-chave: Orientação Profissional; Ensino Médio; Psicologia Brasileira.

\begin{abstract}
With the theme of vocational guidance (OP) in secondary education, we elaborate this article with the objective of carrying out a systematic review on Brazilian psychology studies about this topic. For this, we used five databases: LILACS (Latin American and Caribbean Literature in Health Sciences), Index Psi, SciELO (Scientific Electronic Library Online), PePSIC and PsycINFO. At the end of the analysis, there were 29 articles, being 4 theoretical articles and 25 empirical articles. The most used theoretical bases were positive psychology and sociocognitive and communitarian theories. In the empirical articles, we verified that the most frequent theme was the use of scales, that aim to measure the relation of the factors evaluated by them and the OP. As an example of these scales we can mention: Maturity Scale for Professional Choice - EMEP; Professional Counseling Scale -EAP; and Scale of Attribution and Efficacy for Occupational Activities - EAAOC. The scientific journals that most published works on this subject were those in which OP is the central theme of their publications. It has been observed that in the last years publications on the subject have decreased considerably compared to the last decade.
\end{abstract}

Keywords: Professional Orientation; High School; Brazilian Psycology. 


\section{Introdução}

De acordo com Lassane \& Sparta (2003) a Orientação Profissional (OP) surge no início do século $X X$, com o objetivo se prevenir acidentes e promover 0 aumento da produtividade. No entanto, com o processo de globalização, surgiram muitas transformações permeadas pelas reivindicações sociais. A psicologia, entre as várias áreas do conhecimento, passou a se debruçar sobre a temática da $\mathrm{OP}$, tendo em vista $\circ$ surgimento de questões que envolvem a política, a exclusão social e a necessidade de transformar e superar tal exclusão.

Em sua origem, a OP se dedicava aos estudantes que apresentavam melhores condições financeiras, mas, atualmente, essa concepção tem sido modifica$\mathrm{da}$, e os jovens estudantes de baixa renda passaram a se beneficiar da OP. As políticas de acesso ao ensino superior e permanência nele têm favorecido tal movimento. Muitos autores evidenciam que as pesquisas relacionadas à $O P$ de jovens de camadas populares devem ser ampliadas (Bardagi, Arteche \& Neiva-Silva, 2005; Bastos, 2005; Dias \& Soares, 2007; Ribeiro, 2003; Valore, 2010).

Pesquisadores como Uvaldo e Silva (2010) corroboram a ideia de que a orientação profissional deve fazer parte do projeto político pedagógico das escolas e, contribuir para o desenvolvimento de uma educação voltada para construção de projetos profissionais e de vida.

Outro aspecto a ser considerado é a função do corpo docente na formação do perfil profissional de seus discentes (Ferreira, Nascimento, \& Montaine, 2009). Educadores e professores devem desenvolver nos estudantes as competências necessárias para torná-los aptos a realizarem escolhas, mais precisamente na fase escolar, relacionadas à profissão que irão seguir (Oliveira, 2000; Soares, 2000).

A escolha profissional se consolida ao longo da vida, em um processo que se inicia na infância e segue até envelhecermos, por meio de diversas etapas do desenvolvimento vocacional e tarefas evolutivas, de acordo com Super, Savickas e Super (1996). Já a orientação profissional baseia-se na promoção do autoconhecimento e no fornecimento de informação profissional (Sparta, 2003).

No Brasil, a escolha profissional é estudada a partir de vários contextos. Alguns estudos abordam a escolha profissional por determinados cursos universitários (Magalhães, Straliotto, Keller, \& Gomes, 2001; Sales, \& Chamon, 2011 ; Ribeiro, Leal, Diamantino, \& Bianchi, 2011 ; Tartuce, Nuneso, \& Almeida, 2010). Outros apresentam as imagens sociais das profissões e carreiras (Silva, Borges, \& Barbosa, 2014). Alguns tratam do desenvolvimento de carreira com alunos de graduação (Dias, \& Soares, 2012; Luna, Bardagi, Gaikoski, \& Melo, 2014; Oliveira, \& Melo-Silva, 2010). Ainda há os que analisam o processo de escolha e os interesses profissionais (Bardagi, Santos, \& Luna, 2014; Feijó, \& Magnan, 2012; Gramani, \& Scrich, 201 2; Magalhães, 2008; Nepomuceno, \& Witter, 2010; Noronha, \& Ambiel, 2015; Santos, 2005; Silva, 2004). Além disso, temos os estudos a respeito da orientação profissional no contexto de jovens de baixa renda (Costa, 2007).

A OP tem o propósito de possibilitar a discussão acerca do processo de escolha. Quanto à experiência em orientação profissional Soares, Krawulski, Dias, e D'avila (2007) expressam que "o homem objetivamente transforma o mundo e subjetivamente é também transformado enquanto atua" (p.750). Ou seja, mesmo que o meio limite o indivíduo, "a escolha está sempre presente, objetiva e subjetivamente, e faz parte das ações humanas" (p.750). Segundo as autoras, alguns fatores interferem na escolha de uma profissão, ou seja, o quanto se estar informado acerca das carreiras profissionais e cursos, o fato de ter a visão do ensino superior como meio de se destacar socialmente, a preocupação com a falta de êxito nos processos seletivos e consequentemente com o futuro acadêmico e profissional. Portanto, as autoras supracitadas concluem que 0 processo de 
preparação para uma vaga na universidade, se relaciona com $\circ$ processo de orientação profissional, onde a orientação profissional colabora com a escolha profissional ao favorecer a motivação para - estudo, além da redução da ansiedade, quando propõe a socialização das inquietações e dúvidas.

A OP pode ser realizada com os mais diversos objetivos, bem como diferentes populações, mas o que deve ser considerado é o fato de o sujeito ser capaz de fazer suas próprias escolhas, mesmo que esteja em condições limitadas (Soares, 2000), e isso ocorre geralmente ao se concluir a última etapa da educação básica, que é o ensino médio.

A partir daí, surge a importância de se pesquisar como a psicologia brasileira vem abordando a OP no ensino médio, fase em que o processo de escolhas determinará o rumo dado pelo estudante à sua vida acadêmica e profissional. Tendo em vista que a OP visa o desenvolvimento dos indivíduos, facilitando as escolhas, a elaboração de projetos de vida e o processo de tomada de decisão, podendo ser realizada, inclusive, em escolas, cujo público alvo seriam os jovens em início de carreira (Silva, 2010).

É importante destacar que dentre as bases de dados pesquisadas foi encontrado apenas um estudo cujo interesse se assemelha ao nosso, no entanto, restringe a busca ao período de 2011 a 2015 e não tem como foco a OP no ensino médio (Ambiel, Campos \& Campos, 2017). Desta forma, o presente estudo objetivou realizar uma revisão sistemática, com base na produção do conhecimento acerca da orientação profissional no ensino médio na psicologia brasileira.

\section{Método}

Para iniciarmos a busca nas bases de dados não especificamos o período em que os artigos foram publicados, minimizando a possibilidade de excluir estudos relevantes que tenham sido publicados até outubro de 2017, quando a busca foi realizada. Apesar de registrarmos o idioma com o qual $\circ$ artigo foi escrito, não o adotamos como critério. As bases de dados escolhidas para esta revisão sistemática foram: LILACS (Literatura Latino-Americana e do Caribe em Ciências da Saúde), Index Psi, SciELO (Scientific Eletronic Library Online), PePSIC e PsycINFO. Durante a busca utilizamos termos com operadores booleanos, sendo que na LILACS, Index Psi, SciELO e PePSIC admitimos os termos "orientação profissional AND ensino médio". Já na PsyclNFO, utilizamos os seguintes termos "(professional orientation AND high school) AND (Brazil OR Brazilian OR portuguese)".

Os critérios de inclusão para que $\circ$ artigo fizesse parte da revisão sistemática, se resumiram nos seguintes: 1) ter como tema principal a orientação profissional e o ensino médio e; 2 ) ter relação com a psicologia brasileira. $O$ título, o resumo e as palavras-chave dos artigos foram analisados. Além disso, consideramos o nome e propósito das revistas, sendo incluídos todos os estudos publicados em periódicos brasileiros de Psicologia, ou naqueles em que a Psicologia fosse considerada uma das áreas de publicação. Dessa forma atendemos aos critérios de inclusão. Excluímos os estudos cujo texto completo não estivesse disponível na internet. Além disso, também excluímos estudos duplicados entre as bases pesquisadas.

Foi realizada a leitura dos resumos e dependendo da escassez de informações lemos outras partes dos artigos como, por exemplo, o método e os resultados. Consideramos o tema do estudo, a natureza do estudo (empírico ou teórico), o método, o ano de publicação, o periódico, os autores e os resultados obtidos, que foram organizados em uma planilha (ver Quadro). 


\begin{tabular}{|c|c|c|c|}
\hline \multicolumn{2}{|l|}{ 嘿 } & 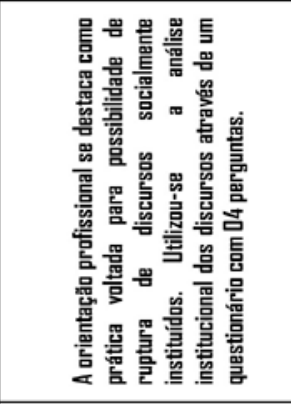 & 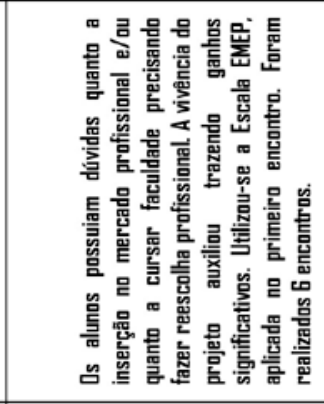 \\
\hline \multicolumn{2}{|l|}{ 崖 } & 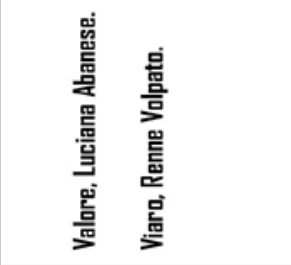 & 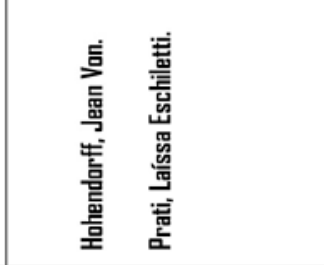 \\
\hline \multicolumn{2}{|l|}{ 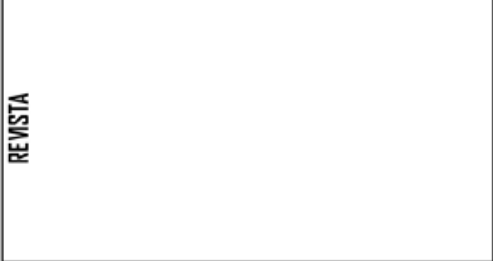 } & 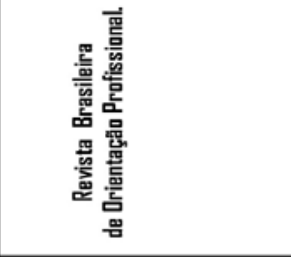 & 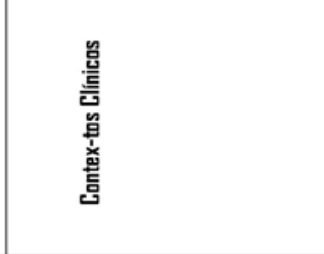 \\
\hline \multicolumn{2}{|l|}{$\frac{1}{4}$} & 总 & 哀 \\
\hline \multirow[b]{3}{*}{ 䇏 } & 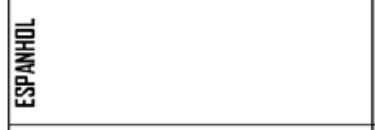 & & \\
\hline & 嵒 & & \\
\hline & 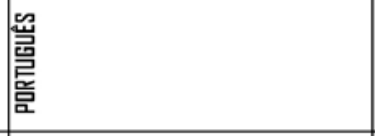 & $x$ & $x$ \\
\hline \multirow[b]{2}{*}{ 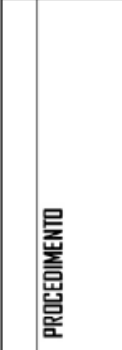 } & 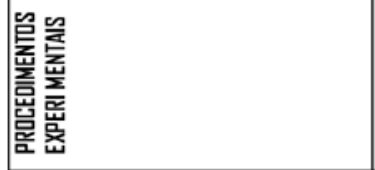 & $x$ & $\times$ \\
\hline & 袈 & & \\
\hline \multirow{3}{*}{ 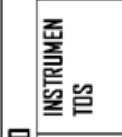 } & Wnu\& & & $x$ \\
\hline & 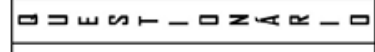 & $\times$ & \\
\hline & 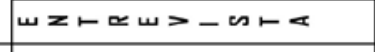 & & \\
\hline \multirow{2}{*}{ 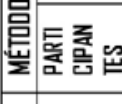 } & - & & \\
\hline & $\operatorname{sos} w \times$ a & 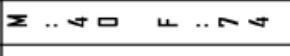 & 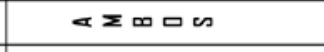 \\
\hline \multicolumn{4}{|l|}{ 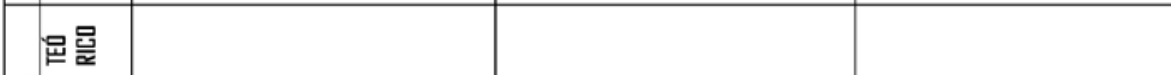 } \\
\hline \multirow{2}{*}{ 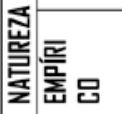 } & 玉ーヘトロ & $\times$ & $x$ \\
\hline & 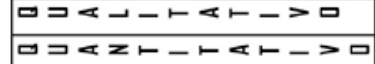 & & \\
\hline \multicolumn{2}{|c|}{$\begin{array}{r}\text { 宮 } \\
\text { 总 } \\
\text { 总 }\end{array}$} & 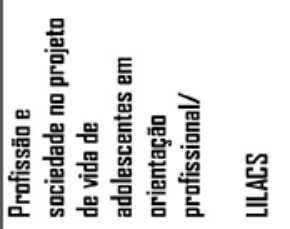 & 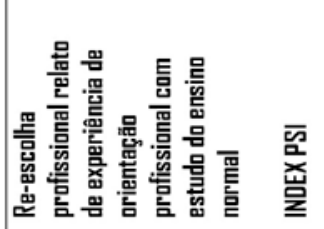 \\
\hline
\end{tabular}




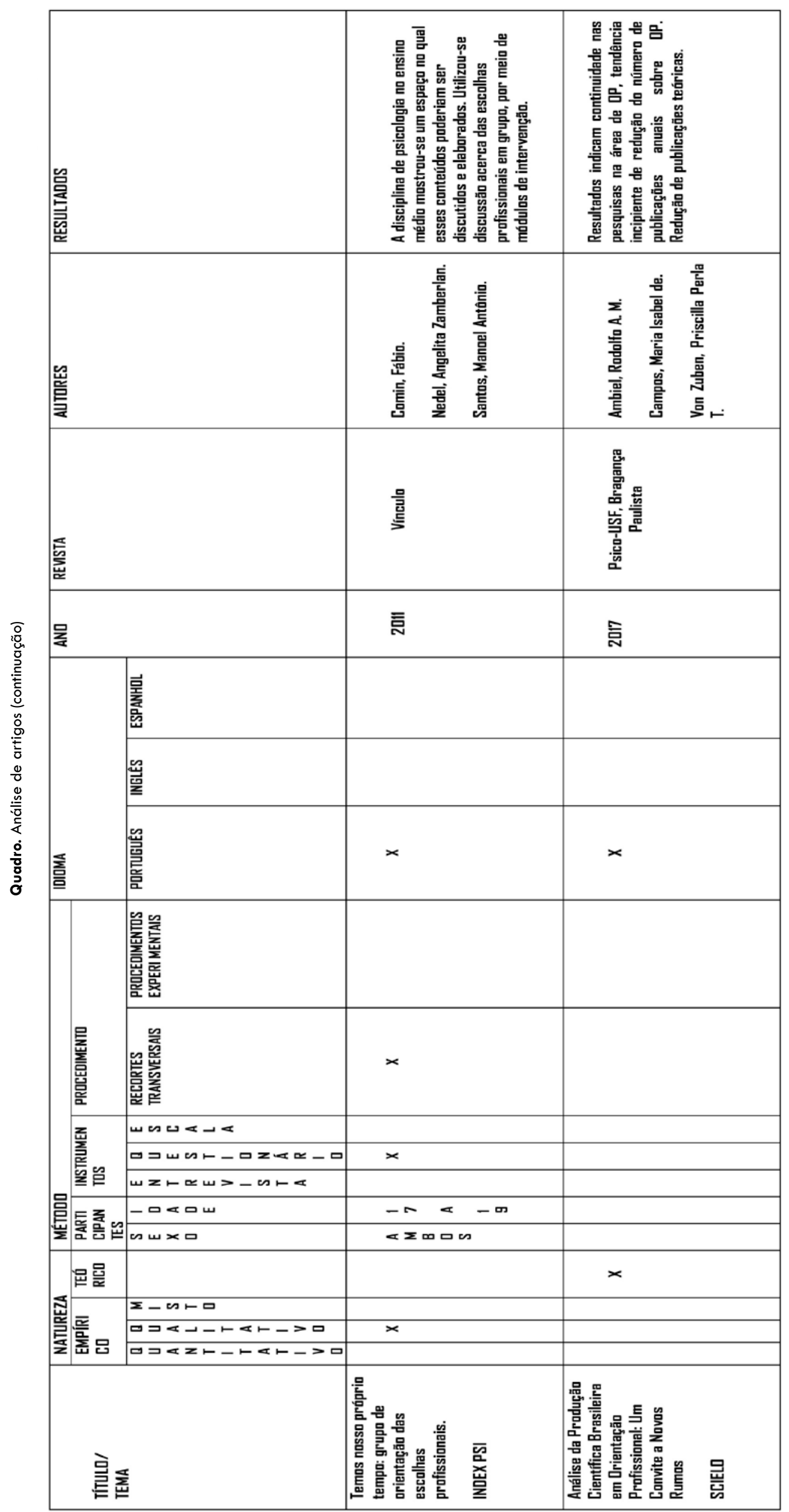




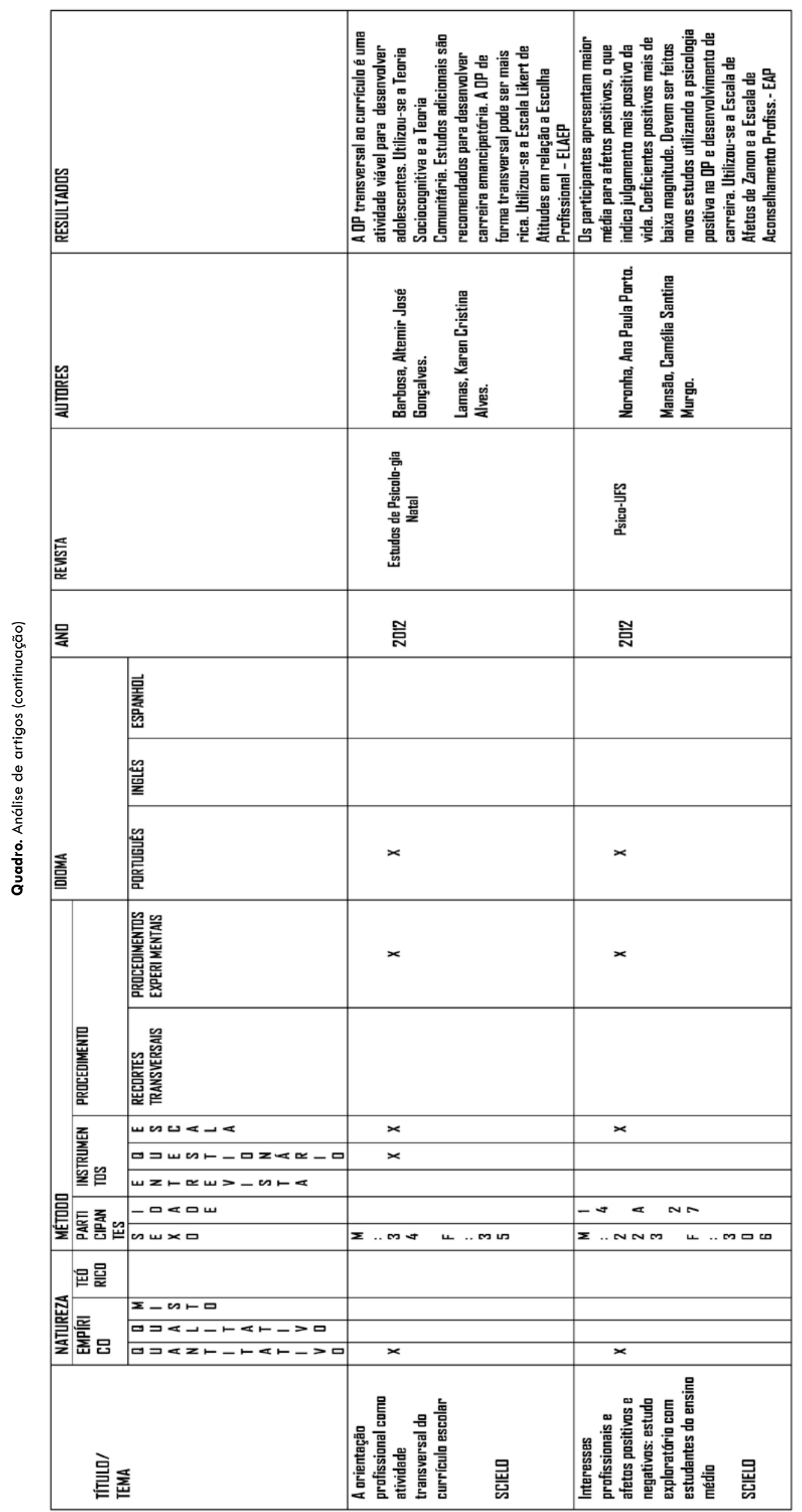




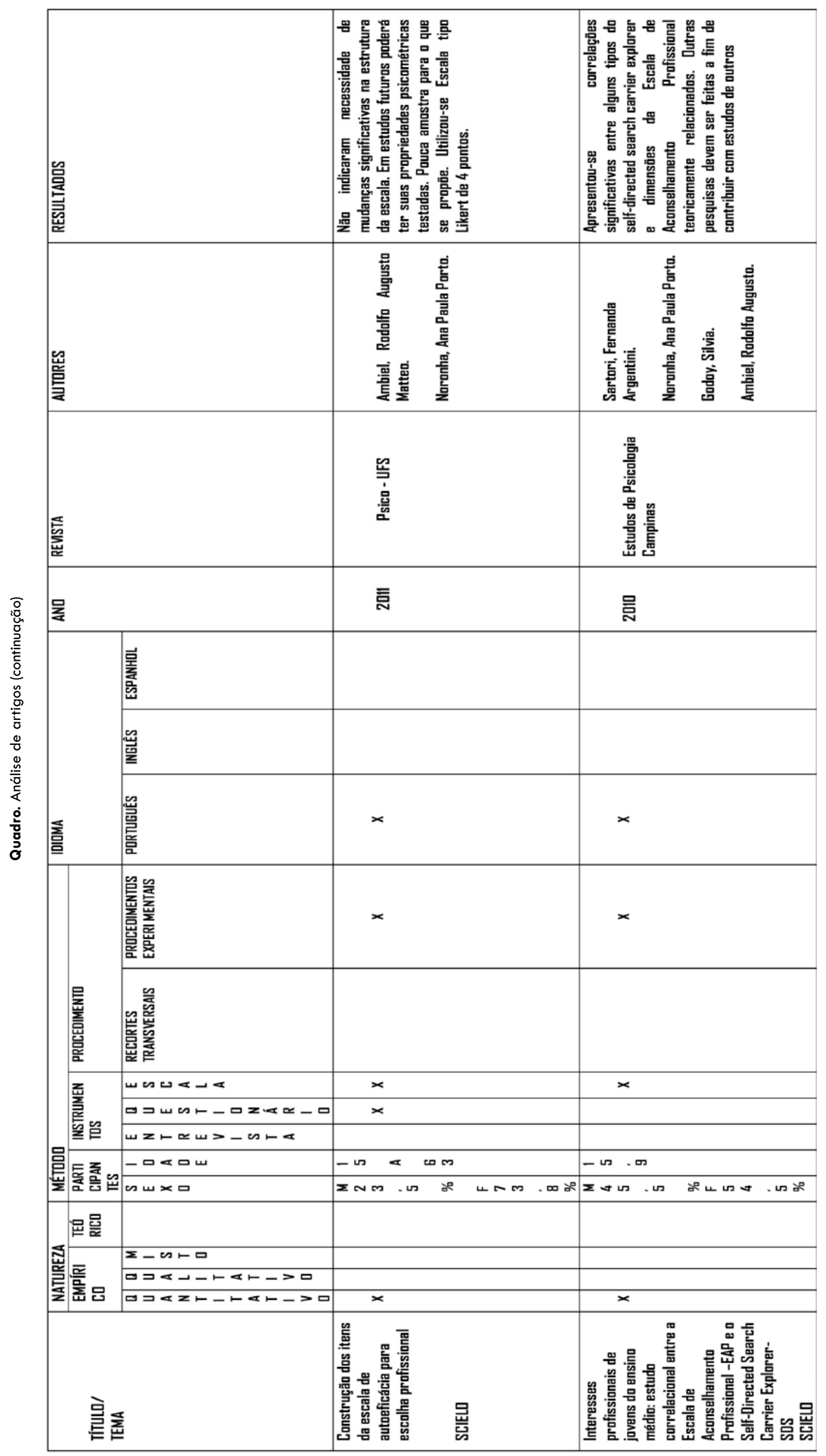

Rev Psi Divers Saúde, Salvador, 2018 Julho;7(2):288-312 


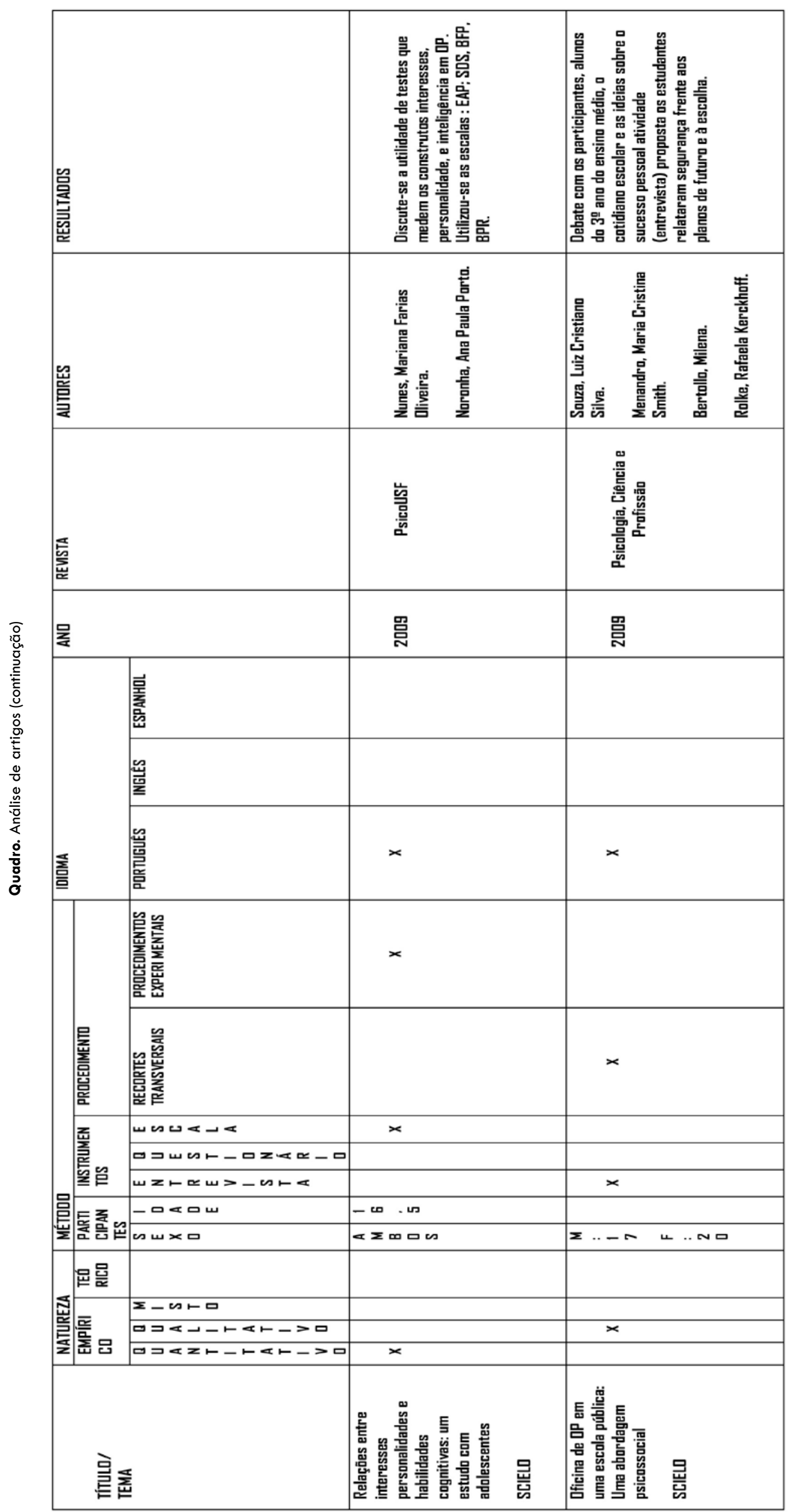

Rev Psi Divers Saúde, Salvador, 2018 Julho;7(2):288-312 


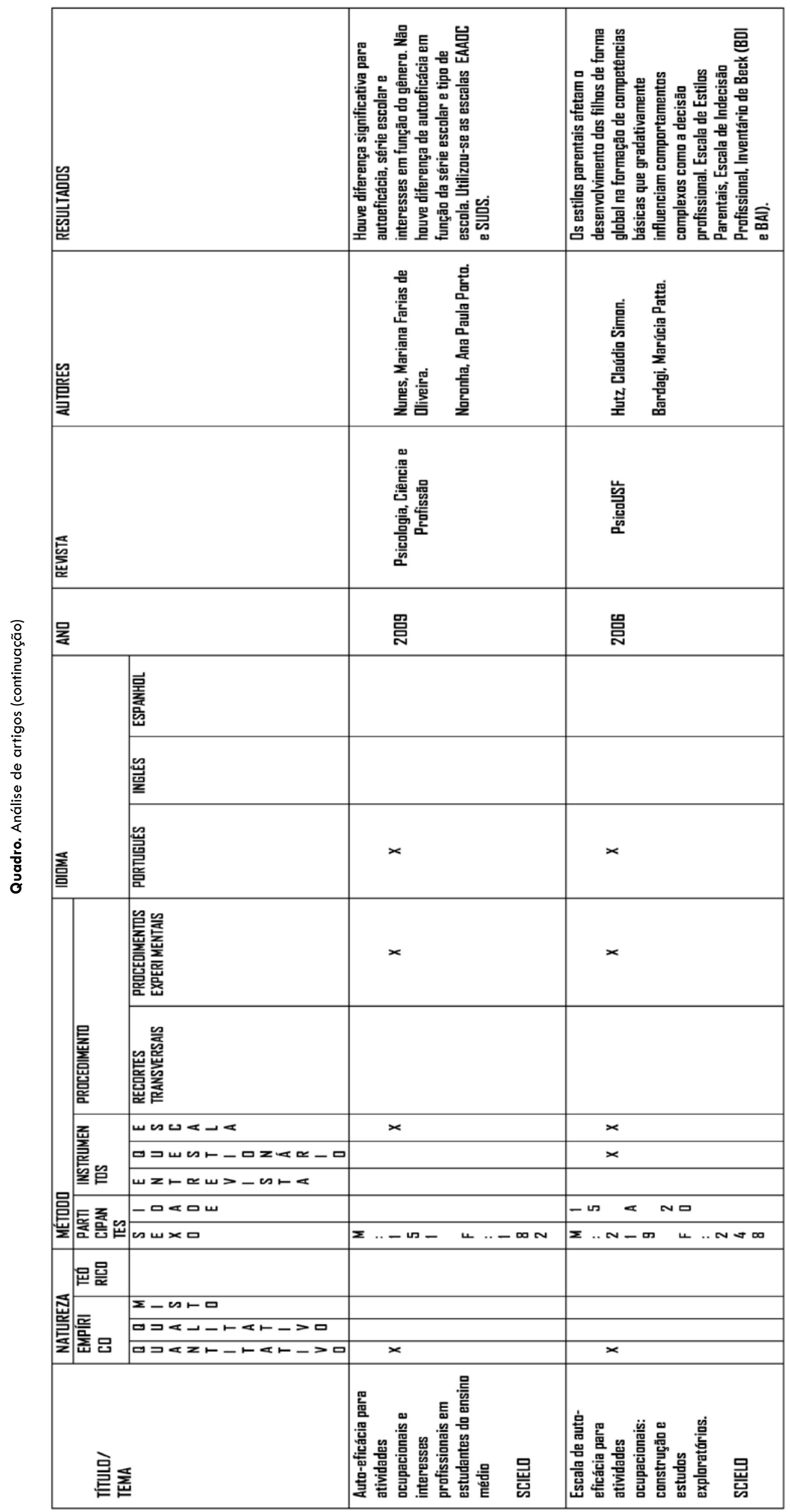

Rev Psi Divers Saúde, Salvador, 2018 Julho;7(2):288-312 


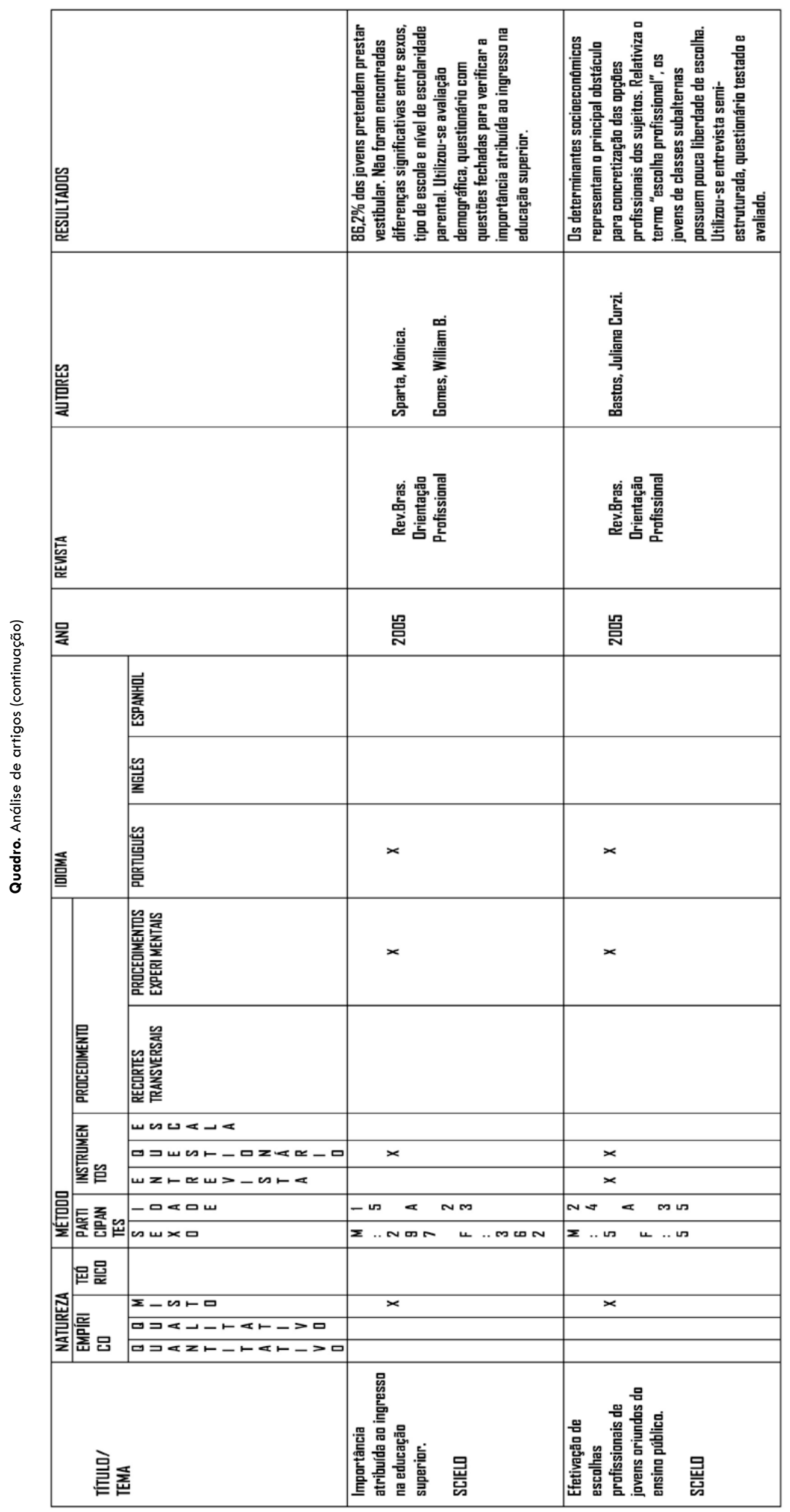

Rev Psi Divers Saúde, Salvador, 2018 Julho;7(2):288-312 


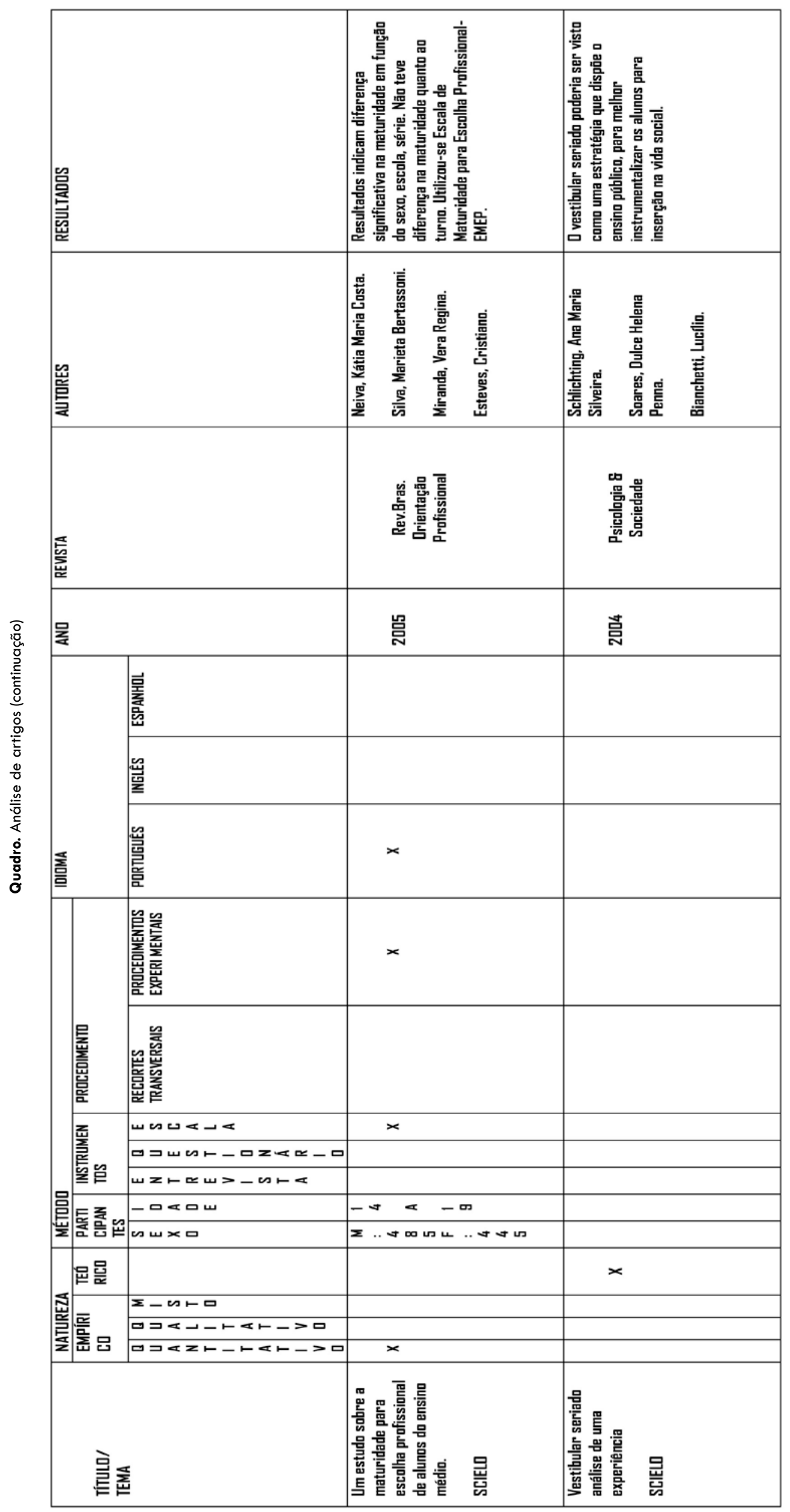

Rev Psi Divers Saúde, Salvador, 2018 Julho;7(2):288-312 


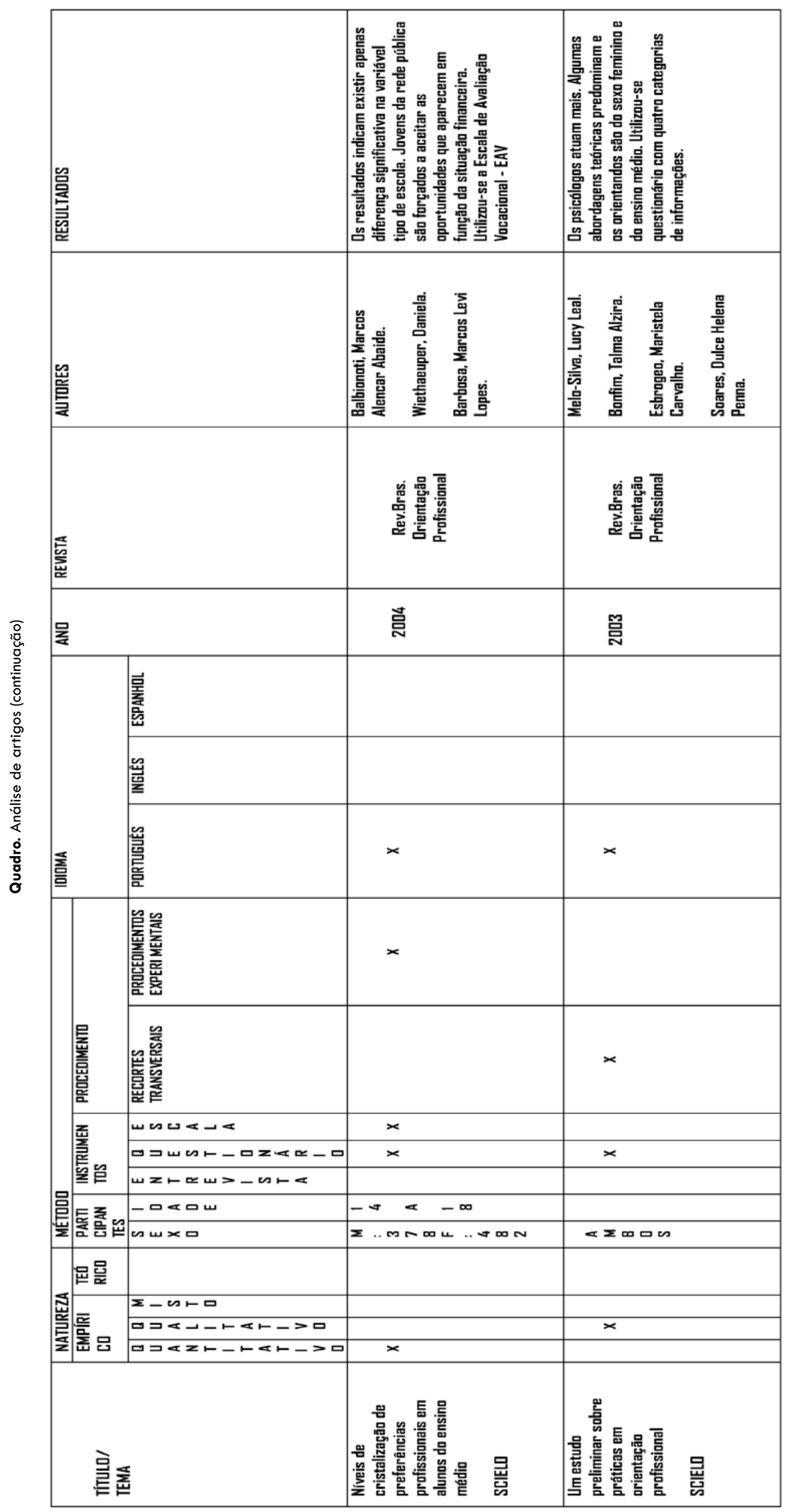

Rev Psi Divers Saúde, Salvador, 2018 Julho;7(2):288-312 


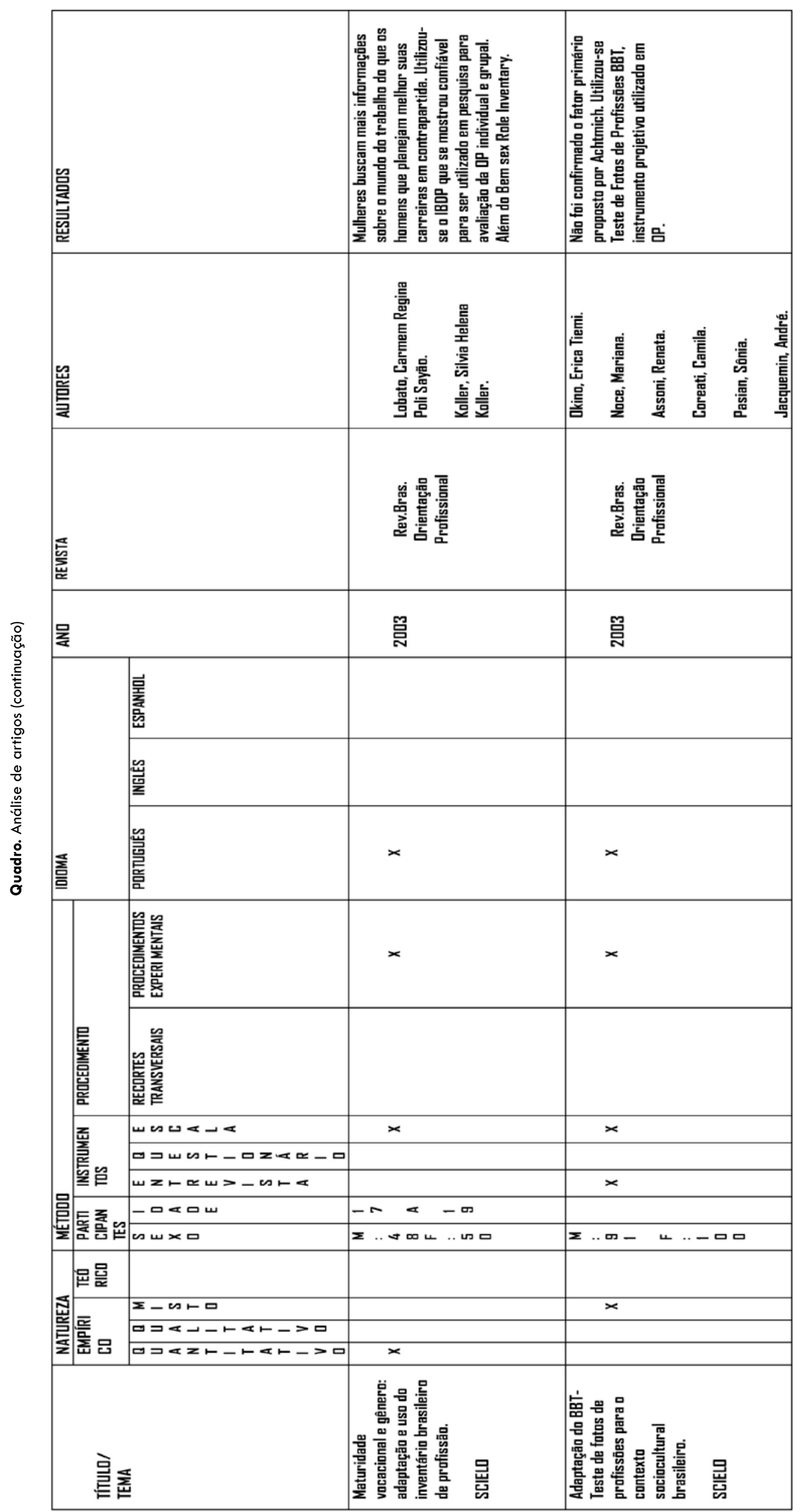




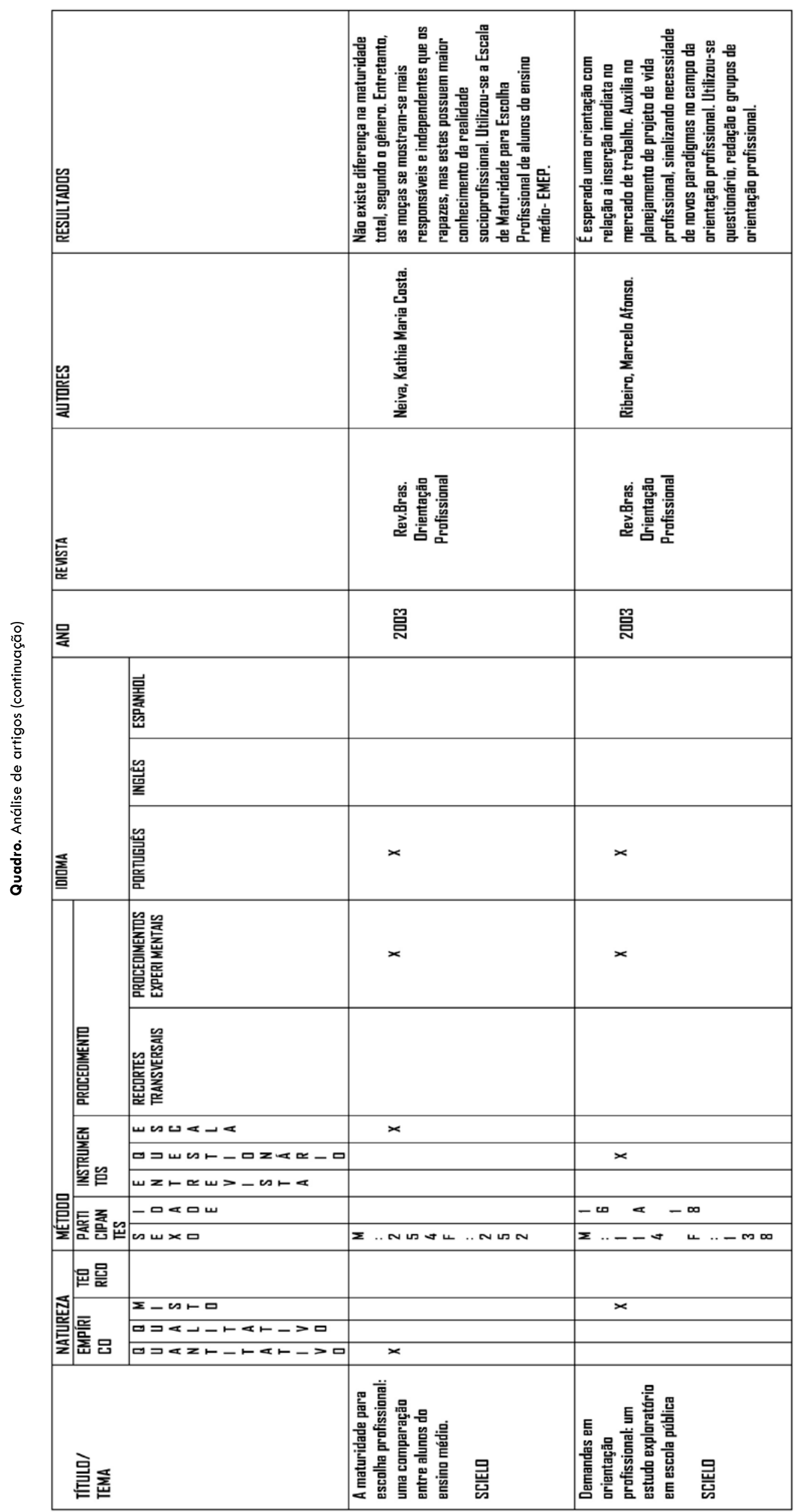

Rev Psi Divers Saúde, Salvador, 2018 Julho;7(2):288-312 


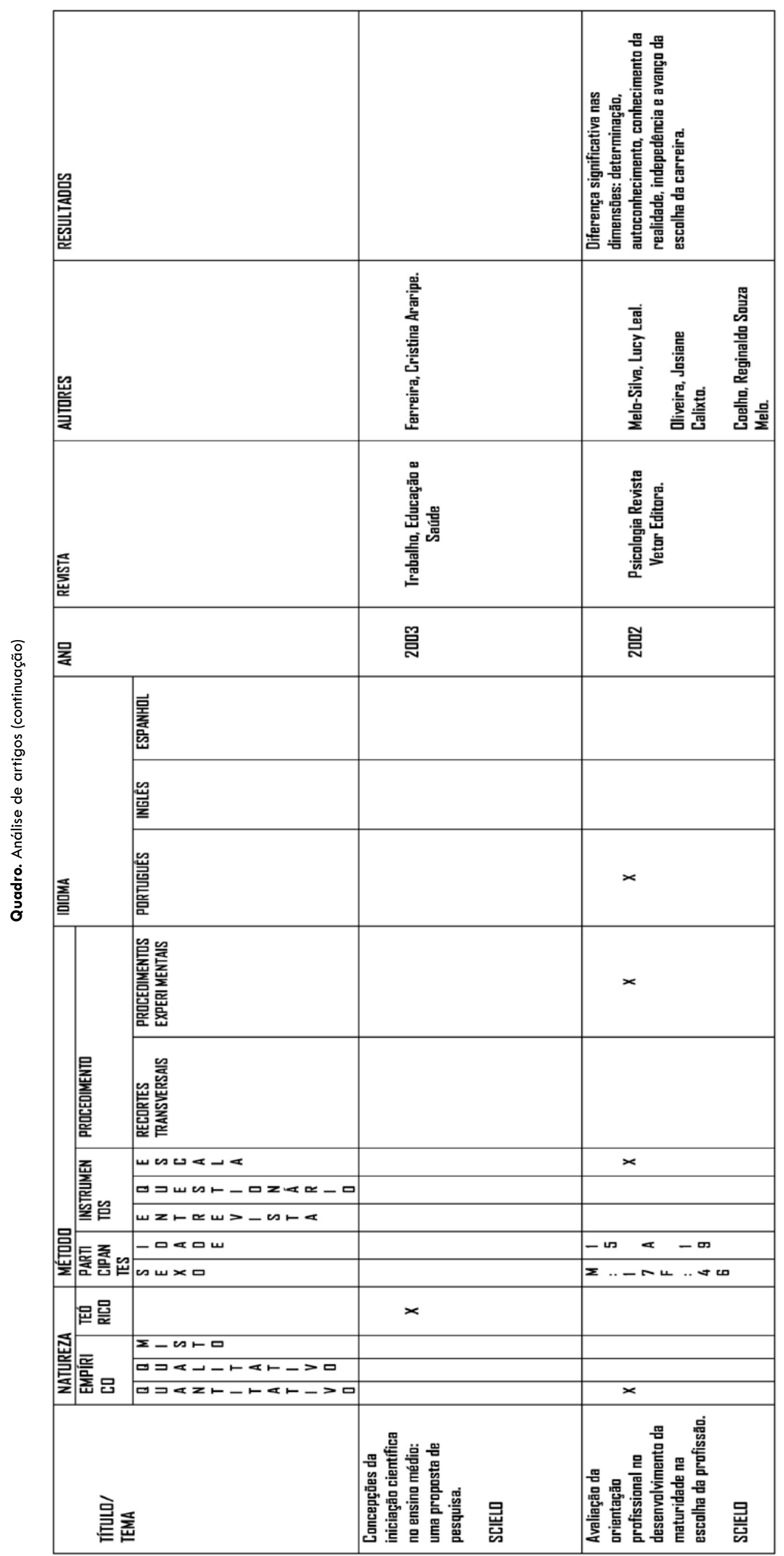

Rev Psi Divers Saúde, Salvador, 2018 Julho;7(2):288-312 


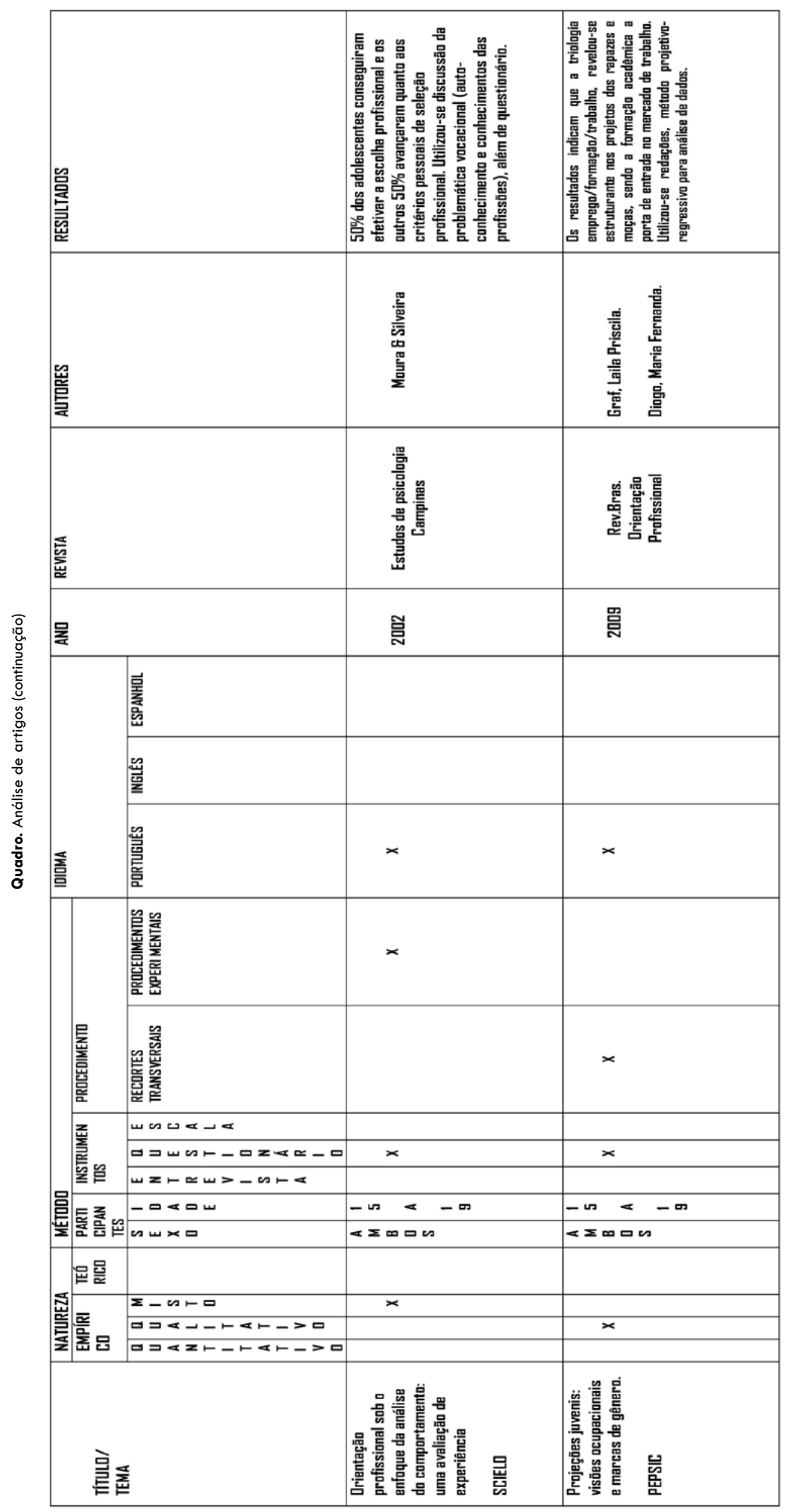

Rev Psi Divers Saúde, Salvador, 2018 Julho;7(2):288-312 


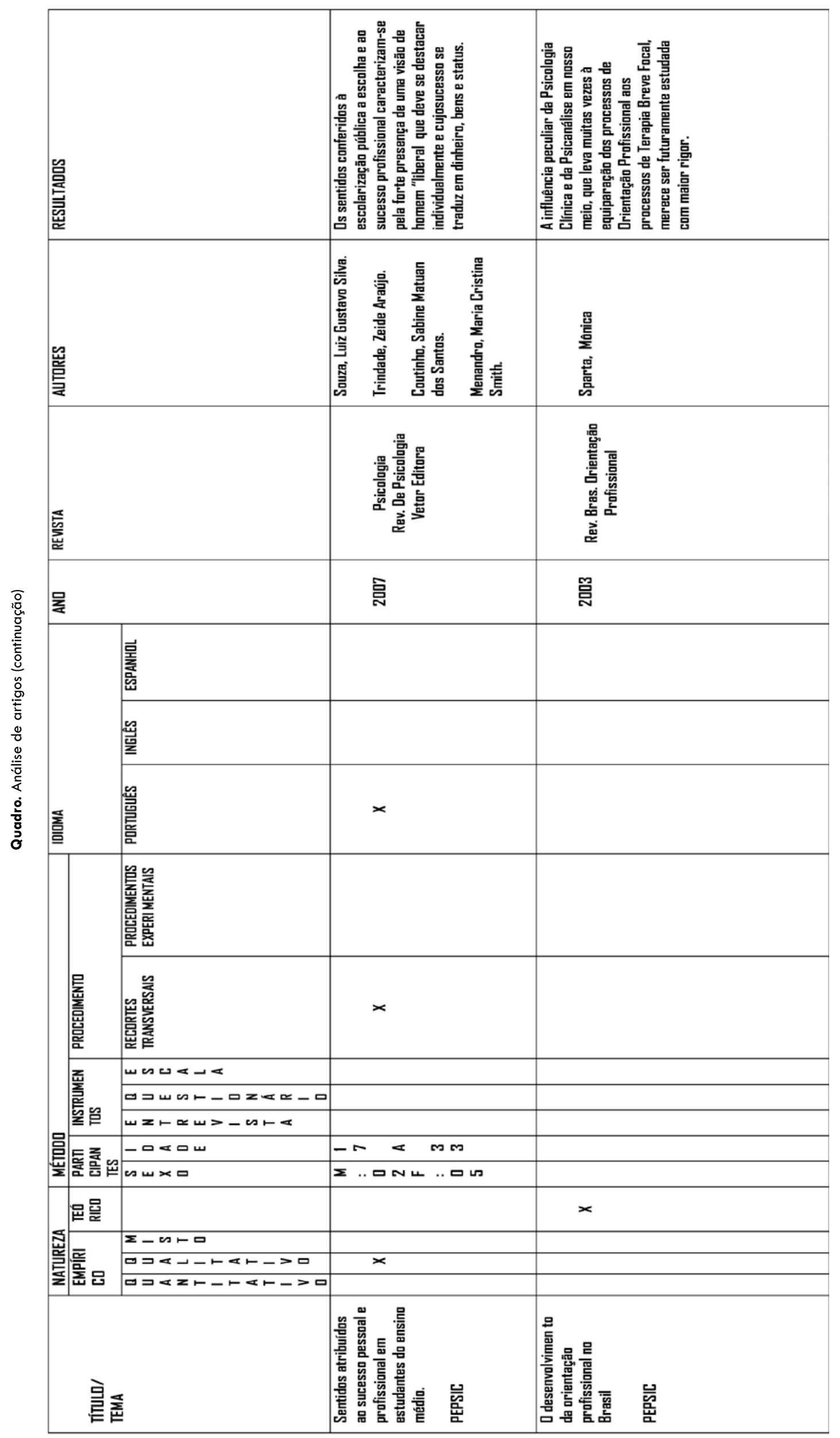




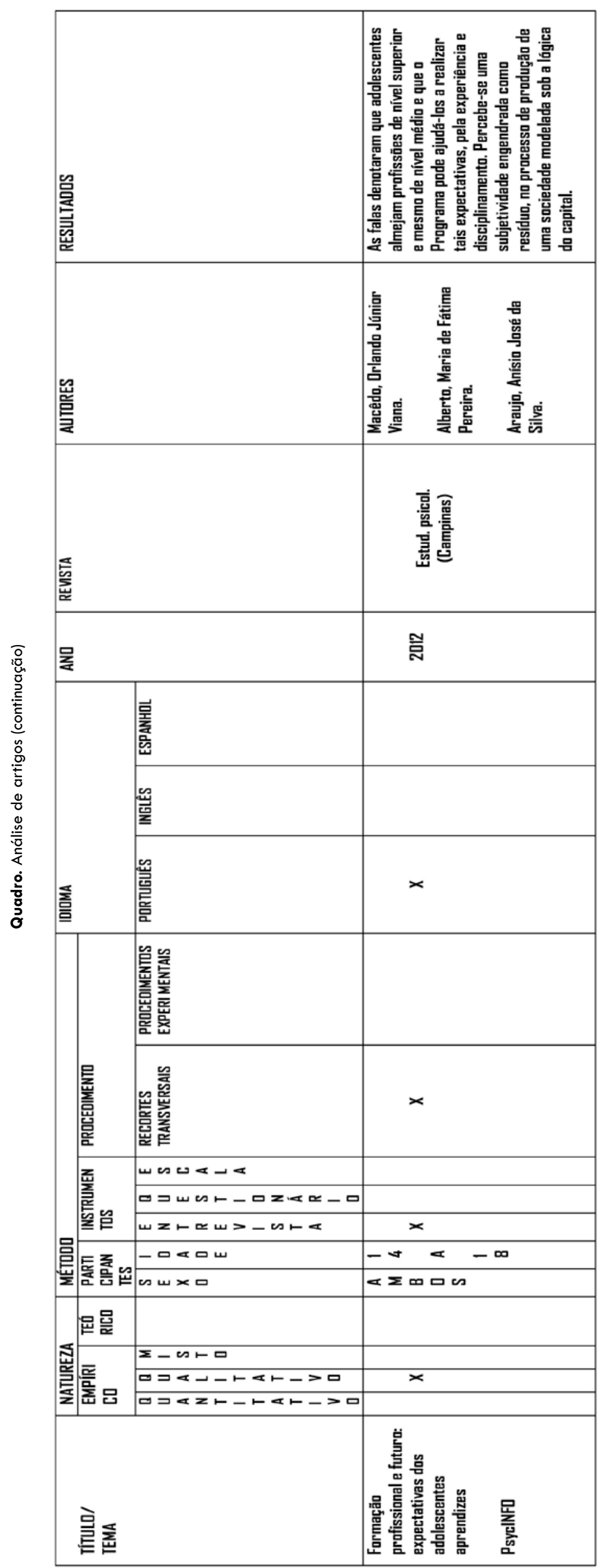

Rev Psi Divers Saúde, Salvador, 2018 Julho;7(2):288-312 


\section{Resultados}

Para a análise dos resultados tomamos como base o ano de publicação dos artigos, os periódicos onde foram publicados e a natureza dos estudos, incluindo aspectos metodológicos e temas tratados. No início obtivemos 57 artigos (LILACS: 01, Index Psi Periódicos Técnico-Científicos: 09, SciELO: 34, PePSIC: 04, PsycINFO:09). Ao aplicarmos os critérios na primeira triagem, excluímos 02 estudos duplicados entre as bases. Desse modo restaram 55 artigos, dos quais 25 não atenderam aos critérios de inclusão e 01 atendeu aos critérios de exclusão. Foram incluídos na análise principal os 29 artigos restan- tes. Dessa forma, obtivemos um banco final constituído por 29 artigos.

Mesmo não excluindo estudos relevantes durante a busca, que contou com todas as publicações acerca do tema publicadas até outubro de 2017 , ocorreu uma incidência maior de trabalhos publicados nas últimas duas décadas (ver Gráfico). Os anos que apresentaram maior índice de publicações foram 2003, 2009 e 2011, com 07, 04 e 04 artigos publicados respectivamente. Já entre os anos de 2013 e 2016 não foram observadas publicações acerca do tema nas bases de dados pesquisadas.

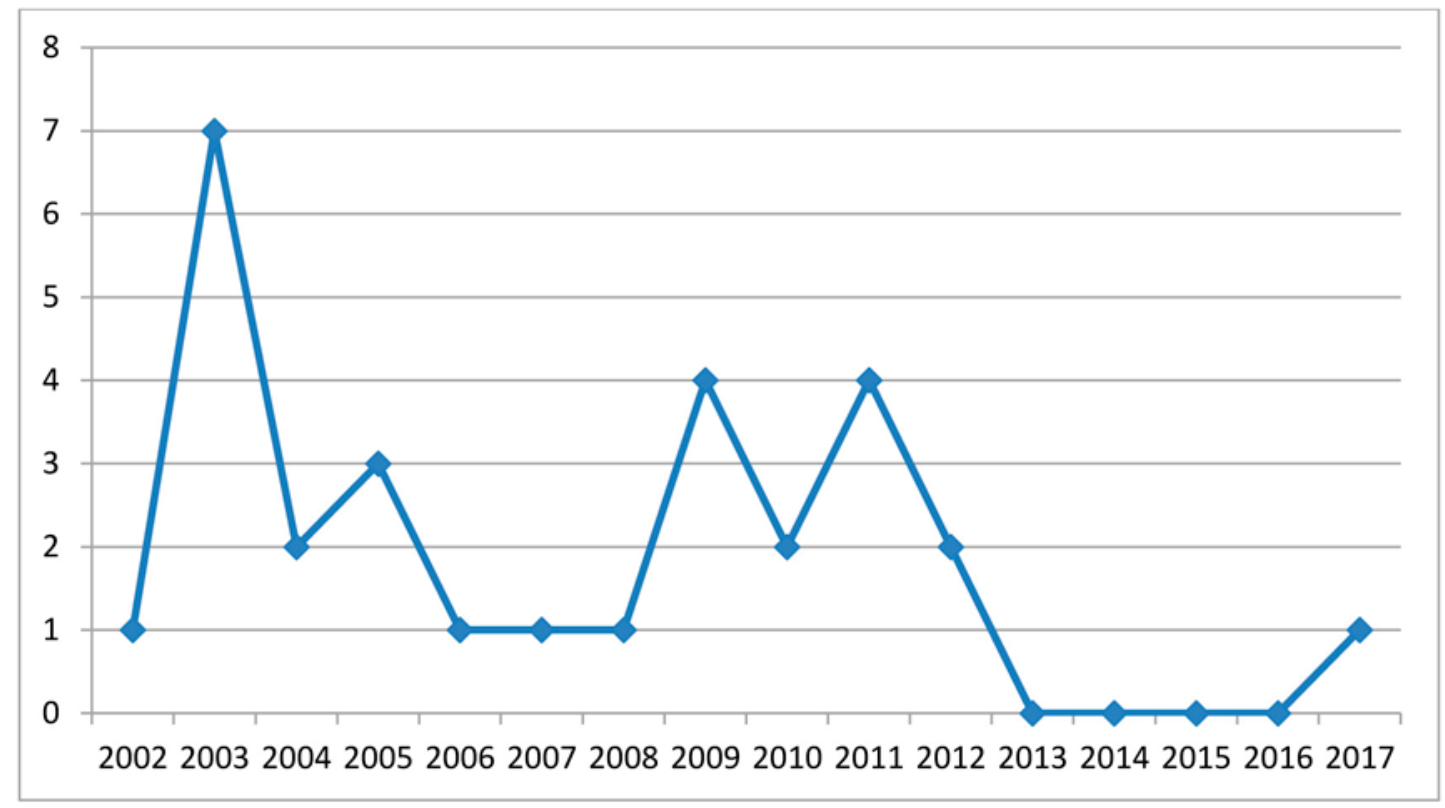

Gráfico. Número de artigos publicados por ano.

As 11 revistas diferentes, nas quais os 29 artigos foram publicados, são editadas no Brasil em português brasileiro. Em 07 periódicos tivemos apenas um artigo publicado sobre o tema. A revista que mais se destacou foi a Revista Brasileira de Orientação Profissional com 12 publicações, seguida das revistas Psico-USF, Psicologia, Ciência e Profissão e Estudos de Psicologia (Campinas) com 06, 02 e 02 artigos publicados respectivamente. A primeira revista é direcionada para a temática pesquisada (ver Tabela). Essa característica pode ajudar a explicar o elevado número de artigos sobre orientação profissional publicados por ela. 
Tabela. Número de Artigos Publicados por Revista, com Avaliação segundo o Qualis Periódicos da Capes entre parênteses.

\begin{tabular}{|c|c|c|}
\hline REVISTAS (QUALIS) & ARTIGOS & REFERÊNCIAS \\
\hline Psico-USF (A2) & 06 & $\begin{array}{l}\text { Ambiel et al (2017); Noronha \& } \\
\text { Mansão (2012); Ambiel \& Porto } \\
\text { (2011); Nunes \& Noronha } \\
\text { (2009); } \\
\text { Ambiel e Noronha (2011); Hutz } \\
\text { \& Bardagi (2006) }\end{array}$ \\
\hline $\begin{array}{l}\text { Psicologia, Ciência e Profissão } \\
\text { (A2) }\end{array}$ & 02 & $\begin{array}{l}\text { Souza et al (2009); Nunes \& } \\
\text { Noronha (2009) }\end{array}$ \\
\hline $\begin{array}{l}\text { Revista Brasileira de Orientação } \\
\text { Profissional (A2) }\end{array}$ & 12 & $\begin{array}{l}\text { Lobato \& Koller (2003); Melo- } \\
\text { Silva et al (2003); Neiva (2003); } \\
\text { Okino et al (2003); Ribeiro } \\
\text { (2003); Balbionoti et al (2004); } \\
\text { Bastos (2005); Neiva et al } \\
\text { (2005); Sparta \& Gomes } \\
\text { (2005); Sparta (2003); Valore \& } \\
\text { Viaro (2007); Graf \& Diogo } \\
\text { (2009). }\end{array}$ \\
\hline Psicologia \& Sociedade (A2) & 01 & Schlichting et al (2004) \\
\hline Psicologia Teoria e Prática (A2) & 01 & Santos et al (2011) \\
\hline
\end{tabular}

\begin{tabular}{lll}
\hline Vínculo (B1) & 01 & Comim et al (2011) \\
\hline Paidéia - Ribeirão Preto (A1) & 01 & Nunes \& Noronha (2008) \\
\hline $\begin{array}{l}\text { Estudos de Psicologia (Campinas) } \\
\text { (A1) }\end{array}$ & 02 & $\begin{array}{l}\text { Sartori et al (2010) } \\
\text { Moura \&Silveira (2002) }\end{array}$ \\
\hline $\begin{array}{l}\text { Estudos de Psicologia (Natal) } \\
\text { (A1) }\end{array}$ & 01 & Barbosa \& Lamas (2012) \\
\hline $\begin{array}{l}\text { Trabalho, Educação e Saúde } \\
\text { (B1) }\end{array}$ & 01 & Ferreira (2003) \\
\hline Contextos Clínicos (B1) & 01 & Hohendorff \& Prati (2010) \\
\hline TOTAL & 29 & \\
\hline
\end{tabular}

Nota: Capes - Comissão de Aperfeiçoamento de Pessoal do Nível Superior

Em relação à classificação das revistas no Qualis Periódicos da última avaliação quadrienal da Capes, $72,7 \%$ das revistas foram classificadas no estrato $A$, sendo 05 delas $A 2$ e 03 delas $A 1$. Enquanto 27,3\% das revistas foram classificadas no estrato $B$, sendo 03 delas B 1 .

Quanto à natureza dos estudos, 04 são teóricos e 25 são empíricos. A Psicologia Positiva e as teorias sociocognitiva e comunitária, em uma ampla variedade de vertentes, foram as bases teóricas mais utilizadas. O tema mais frequente nos artigos empíricos foi o uso de escalas como: Escala de Maturidade para Escolha Profissional- EMEP; Escala de Aconselhamento Profissional -EAP; e Escala de Atribuição e Eficácia para Atividades Ocupacionais - EAAOC, que visam mensurar a relação dos fatores avaliados com a orientação profissional. Em 12 desses estudos empíricos, ou seja, em $48 \%$ foi utilizado o método quantitativo com procedimentos experimentais. Em 06 estudos foi utilizado o método qualitativo com recortes transversais, o que equivale a 24\%. Outros 07 estudos utilizaram o método misto com procedimentos experimentais, ou seja, $28 \%$ deles. Quando consideradas as descrições de participantes, instrumentos e procedimentos utilizados, os 25 artigos empíricos analisados apresentaram informações metodológicas completas, contando com participantes de ambos os sexos, sendo o sexo feminino o mais prevalente. Os outros 04 artigos são teóricos e possuem uma metodologia própria.

As escalas, como instrumentos, foram predominantes nos estudos empíricos, estando presente em 14 deles, sendo 14 estudos do tipo quantitativo e 02 estudos do tipo misto. Os questionários estiveram presentes em 12 estudos empíricos, sendo 04 estudos do tipo quantitativo, 03 estudos do tipo qualitativo e 05 estudos do tipo misto. Grande parte dos questionários foi produzida especificamente para as pesquisas nas quais foram utilizados. As escalas, por sua vez, ou já eram validadas ou foram adap- 
tadas de outros estudos. A Escala de Maturidade para Escolha Profissional foi a mais aplicada, estando presente em quatro estudos (Neiva et. al., 2005).

Quanto ao recorte, todos os estudos empíricos qualitativos adotaram recortes transversais. Tendo em vista, segundo (Richardson, 1999), que os dados foram coletados em um ponto no tempo, com base em uma amostra selecionada para descrever uma população em um determinado momento.

Ainda em relação ao método, em $64 \%$ dos estudos empíricos, ou seja, em 16 artigos as pesquisas foram realizadas com adolescentes, e em $16 \%$, ou seja, em 04 deles, os participantes eram adultos.

A temática orientação profissional relacionada ao ensino médio esteve presente em $23,91 \%$ dos artigos pesquisados. Diferentes autores vêm discutindo - papel e as falhas da escola junto ao ensino médio e concordam que a preocupação central com a aprovação no vestibular tem empobrecido o estímulo ao comportamento exploratório vocacional e ao desenvolvimento de projetos profissionais entre os jovens, o que os leva a fazer escolhas pautadas basicamente na fantasia e em estereótipos (Bardagi, Lassance \& Paradiso, 2003; D'avila \& Soares, 2003).

Em 03 estudos contamos com o conceito de maturidade profissional relacionado à escolha profissional. Neiva $(1998,1999)$ partindo das ideias de Super (1973), Super e Thompson (1979) e Crites (1978), interessou-se por estudar, especificamente, a noção de maturidade para a escolha profissional. Para esta autora, a maturidade para a escolha profissional corresponde a um conjunto de atitudes e conhecimentos que $\circ$ indivíduo deve adquirir, a fim de elaborar uma escolha profissional madura e consciente. De acordo com esta autora, a maturidade para a escolha profissional é composta por duas dimensões: atitude e conhecimento. A dimensão atitude é dividida em três subdimensões: a) Determinação para a escolha, que se refere a quanto o indivíduo está definido e seguro com relação à escolha profissional; b) Responsabilidade para a escolha profissional, que se refere a quanto o sujeito está engajado no processo de escolha profissional e empreende ações para tomar esta decisão; e c) Independência, que se refere a quanto $o$ indivíduo processa esta decisão de forma independente, sem influência de outras pessoas (familiares, professores, amigos, mídia etc). A dimensão conhecimento é dividida em duas subdimensões: a) Autoconhecimento, que se refere ao conhecimento que o indivíduo possui sobre vários aspectos de si mesmo e que são importantes para a escolha profissional, dentre eles: interesses, habilidades e valores; e b) Conhecimento da Realidade Educativa e Socioprofissional, que se refere ao conhecimento que o sujeito tem das instituições educativas, das profissões, do mercado de trabalho etc.

Dos 04 artigos teóricos analisados, 01 deles é bem atual e fez uma análise da produção científica brasileira em Orientação Profissional (Ambiel, et al 2017). O artigo se propôs a avaliar a produção científica brasileira na área da orientação profissional de 2011 a 2015, dando prosseguimento ao trabalho realizado previamente por Noronha e Ambiel (2006) e por Aguiar e Conceição (2012). Segundo - apanhado realizado pelos autores, a continuidade se faz presente nas pesquisas na área de OP. Alguns fatores devem ser considerados: 1) existe uma tendência, mesmo que ínfima, de redução do número de estudos atuais sobre OP; 2 ) as publicações de abrangência teórica estão reduzidas desde o último levantamento feito pelos referidos autores; 3) estudos envolvendo a qualidade das técnicas empregadas, também foram reduzidas; 4) os estudantes de ensino médio e universitários continuam sendo os sujeitos mais presentes nos estudos.

Segundo Aguiar e Conceição (2012) existem espaços que precisam ser preenchidos, a nível de pesquisa nacional, com a temática $O P$, e a forma de se fazer isso é ampliando os estudos que abordem populações variadas, submetendo os serviços de OP a avaliações de eficácia, e promovendo políticas públicas para $O P$.

Portanto, o primeiro passo para o novo rumo a ser dado para pesquisa em OP no Brasil é considerar novas teorias e paradigmas (Savickas et. al., 2009); - segundo é abordar o empreendedorismo como opção de carreira profissional, como sugere Campos, Abbad, Ferreira e Negreiros (2014).

Wright, Silva e Spers (2010) fazem uma projeção, que o empreendedorismo terá uma participação no 
mercado de trabalho em 2020 em torno de 17\% da população economicamente ativa.

Watson e McMahon (2015) sugerem que os pesquisadores da área de OP estudem as modalidades descritas acima, para viabilizar técnicas que possam ser credibilizadas e postas em prática.

Com essas provocações baseadas no estudo de Ambiel, et al (2017), espera-se que a ciência evolua no sentido de preencher os espaços existentes neste campo do conhecimento, identificando novas populações de risco, além de promover o desenvolvimento de novas carreiras que tendem a surgir com a expansão da tecnologia.

\section{Conclusão}

Tendo como objetivo analisar os estudos que a Psicologia brasileira tem publicado sobre orientação profissional e ensino médio no país, realizamos esta revisão sistemática. Durante a busca, percebemos que as revistas que mais publicaram artigos sobre OP e ensino médio foram aquelas nas quais a OP é tema central de suas publicações. Além disso, observamos que, nos últimos anos, as publicações envolvendo o assunto têm diminuído consideravelmente se comparadas à década passada. $O$ potencial que a psicologia possui, como ciência que estuda vários processos, capacita-a para o desenvolvimento de pesquisas para compreensão do objeto desta revisão.

Vale ressaltar que a OP é uma área pouco explorada no país, principalmente no momento atual em que vivenciamos a mudança para nova proposta de ensino médio, quando as escolhas determinarão, com maior antecedência, $\circ$ rumo que o estudante dará à sua vida acadêmica e profissional.

De acordo com a Lei $n^{\circ} 13.415 / 2017$, o currículo do ensino médio será composto pela Base Nacional Comum Curricular e por itinerários formativos, que deverão ser organizados por meio da oferta de diferentes arranjos curriculares, conforme a relevância para o contexto local e a possibilidade dos sistemas de ensino a saber: linguagens e suas tecnologias; matemática e suas tecnologias; ciências da natureza e suas tecnologias; e ciências humanas e sociais aplicadas. Tais itinerários irão atender à multiplicidade de interesses dos estudantes, o aprofundamento acadêmico e a formação técnica profissional. Por isso, a importância de termos programas de orientação profissional voltados às novas demandas dos estudantes do ensino médio, de modo a ampliar suas possibilidades de escolhas profissionais.

Com a não inclusão de teses, dissertações e livros, surgiram algumas limitações ao realizar essa revisão, já que ela ficou restrita aos artigos científicos e alguns estudos estavam apoiados em teses, dissertações e livros. Os descritores utilizados podem não ter abrangido outros trabalhos. Tais limites não comprometem a importância da revisão ou os resultados da mesma. Ao identificar a forma como a Psicologia Brasileira tem investigado a temática da OP no ensino médio, as autoras esperam contribuir com aqueles que pretendem pesquisar acerca deste tema.

\section{Conflitos de interesses}

Nenhum conflito financeiro, legal ou político envolvendo terceiros (governo, empresas e fundações privadas, etc.) foi declarado para nenhum aspecto do trabalho submetido (incluindo mas não limitandose a subvenções e financiamentos, conselho consultivo, desenho de estudo, preparação de manuscrito, análise estatística, etc).

\section{Referências}

Aguiar, F. H. R, \& Conceição, M. I. G. (2012). Análise da produção científica em orientação profissional: Tendências e velhos problemas. Psico-USF, 17(1), 97-107. Recuperado de http://www.scielo.br/pdf/ pusf/v17n1/a1 1v17n1.pdf. doi: 10.1590/S141382712012000100011

Ambiel, R. A. M., Campos, M. I., \& Campos, P.P.T.V.Z. (2017). Análise da produção científica brasileira em orientação profissional: um convite a novos rumos. Psico-USF, 22(1), 133-145. Recuperado de http://www.scielo.br/pdf/pusf/v22nl/21753563-pusf-22-01-00133.pdf. doi: 10.1590/141382712017220112 
Bardagi, M. P., Arteche, A. X., \& Neiva-Silva, L. (2005). Projetos sociais com adolescentes em situação de risco: discutindo o trabalho e a orientação profissional como estratégias de intervenção. In C. Hutz (Org.), Violência e risco na infância e na adolescência: pesquisa e intervenção (pp. 101-146). São Paulo: Casa do Psicólogo.

Bardagi, M. P., Lassance, M. C. P., \& Paradiso, A C. (2003). Trajetória acadêmica e satisfação com a escolha profissional de universitários em meio de curso. Revista Brasileira de Orientação Profissional, 4(1), 153-166. Recuperado de http://pepsic.bvsalud.org/pdf/rbop/ v4n1-2/v4n1-2a13.pdf

Bardagi, M. P., Santos, M. M., \& Luna, I. N. (2014). O desafio da orientação profissional com adolescentes no contexto da modernidade líquida. Revista de Ciências Humanas, 48(2), 263-281. Recuperado de https:// periodicos.ufsc.br/index.php/revistacfh/article/ viewFile/2178-4582.2014v48n2p303/28513. doi: $10.5007 / 2178-4582.2014 \mathrm{v} 48 \mathrm{n} 2 \mathrm{p} 303$

Bastos, J. C. (2005). Efetivação de escolhas profissionais de jovens oriundos do ensino público: um olhar sobre suas trajetórias. Revista Brasileira de Orientação Profissional, 6(2), 31 -43. Recuperado de http://pepsic.bvsalud. org/pdf/rbop/v6n2/v6n2a04.pdf

Campos, E.B.D., Abbad, G. S., Ferreira, C. Z., \& Negreiros, J. L. X. M. N. (2014). Empresas juniores como espaço de apoio à formação profissional de estudantes universitários brasileiros. Revista Psicologia, 14(4), 452-463. Recuperado de http://pepsic.bvsalud.org/ $\mathrm{pdf} / \mathrm{rpot} / \mathrm{v} 14 \mathrm{n} 4 / \mathrm{v} 14 \mathrm{n} 4 \mathrm{a} 11$ 1.pdf

Costa, J. M. (2007). Orientação profissional: um outro olhar. Psicologia USP, 18(4), 79-87. Recuperado de http:// pepsic.bvsalud.org/pdf/psicousp/v18n4/v18n4a05. pdf. doi: $10.1590 /$ S0103-65642007000400005

Crites, J.O. (1978). Carreer Maturity Inventory: Theory and research handbook (2nd ed.). Monterey, C.A.: McGrawHill.

D'Avila, G. T., \& Soares, D. H. P. (2003). Vestibular: fatores geradores de ansiedade na "cena da prova". Revista Brasileira de Orientação Profissional, 4(1), 105-1 16. Recuperado de http://pepsic.bvsalud.org/pdf/rbop/ v4n1-2/v4n1-2a10.pdf

Dias, M. S. L., \& Soares, D. H. P. (2007). Jovem, mostre sua cara: um estudo das possibilidades e limites da escolha profissional. Psicologia Ciência e Profissão, 27(2), 31 6-331. Recuperado de http://www.scielo. $\mathrm{br} / \mathrm{pdf} / \mathrm{pcp} / \mathrm{v} 27 \mathrm{n} 2 / \mathrm{v} 27 \mathrm{n} 2 \mathrm{a} 12$ 2.pdf. doi: $10.1590 /$ S1414-98932007000200012
Dias, M. S. L., \& Soares, D. H. P. (2012). A escolha profissional no direcionamento da carreira dos universitários. Psicologia: Ciência e Profissão, 32(2), 272-283. Recuperado de http://www.scielo.br/pdf/pcp/ v32n2/v32n2a02.pdf. doi: 10.1590/S141498932012000200002

Feijó, A. M. L. C., \& Magnan, V. C. (2012). Análise da escolha profissional: uma proposta fenomenológicoexistencial. Psicologia: Ciência e Profissão, 32(2), 356-373. Recuperado de http://www.scielo.br/pdf/ pcp/v32n2/v32n2a07.pdf. doi:10.1590/S141498932012000200007

Ferreira, A. F., Nascimento, I., \& Fontaine, A. M. (2009). O papel do professor na transmissão de representações acerca de questões vocacionais. Revista Brasileira de Orientação Profissional, 10(2), 43-56. Recuperado de http://pepsic.bvsalud.org/pdf/rbop/v10n2/ v10n2a06.pdf

Gramani, M. C. N., \& Scrich, C. R. (2012). Influência do desempenho educacional na escolha da profissão. Cadernos de Pesquisa, 42(147), 868-883. Recuperado de http://www.scielo.br/pdf/cp/v42n147/12.pdf. doi: $10.1590 /$ s0100-15742012000300012

Lassance, M. C., \& Sparta, M. (2003) A orientação profissional e as transformações no mundo do trabalho. Revista Brasileira de Orientação Profissional, 4(1-2), 13-19. Recuperado de http://pepsic.bvsalud. org/pdf/rbop/v4n1-2/v4n1-2a03.pdf

Lei $n^{\circ} 13.415$, de 16 de fevereiro de 2017 . Altera as Leis nos 9.394, de 20 de dezembro de 1996, que estabelece as diretrizes e bases da educação nacional, e 11.494 , de 20 de junho 2007, que regulamenta o Fundo de Manutenção e Desenvolvimento da Educação Básica e de Valorização dos Profissionais da Educação, a Consolidação das Leis do Trabalho - CLT, aprovada pelo Decreto-Lei no 5.452, de 10 de maio de 1943, e o Decreto-Lei no 236, de 28 de fevereiro de 1967; revoga a Lei no 11.161, de 5 de agosto de 2005; e institui a Política de Fomento à Implementação de Escolas de Ensino Médio em Tempo Integral. Recuperado de http:www.planalto.gov.br/ccivil_03/_ ato $2015-2018 / 2017 /$ lei/113415.htm

Luna, I. N., Bardagi, M. P., Gaikoski, M. M., \& Melo, F. S. (2014). Empresas juniores como espaço de desenvolvimento de carreira na graduação: reflexões a partir de uma experiência de estágio. Revista Psicologia Organizações e Trabalho, 14(4), 441 -451. Recuperado de http://pepsic.bvsalud.org/pdf/rpot/ v14n4/v14n4a10.pdf 
Magalhães, M. O. (2008). Relação entre ordem de nascimento e interesses vocacionais. Estudos de Psicologia, 25(2), 203-210. Recuperado de http:// www.scielo.br/pdf/estpsi/v25n2/a05v25n2.pdf. doi: 10.1590/S0103-166X2008000200005

Magalhães, M., Straliotto, M., Keller, M., \& Gomes, W. B. (2001). Eu quero ajudar as pessoas: a escolha vocacional da psicologia. Psicologia: Ciência e Profissão, 21 (2), 10-27. Recuperado de http://www.scielo.br/scielo.php?script=sci_ arttext\&pid=S1414-98932001000200003. doi:10.1590/S1414-98932001000200003

Neiva, K. M. C.(1998). Escala de Maturidade para a Escolha Profissional (EMEP): Estudo de validade e fidedignidade. Revista Unib, 6, 43-61.

Neiva, K. M. C. (1999). Escala de Maturidade para a Escolha Profissional (EMEP): Manual. São Paulo: Vetor Editora.

Neiva, K. M. C., Silva, M. B., Miranda, V. R., \& Esteves, C. (2005). Um estudo sobre maturidade para escolha profissional de alunos do ensino médio. Revista Brasileira de Orientação Profissional, 6(1), 1-14. Recuperado de http://pepsic.bvsalud.org/pdf/rbop/ v6n1/v6nla02.pdf

Nepomuceno, R. F., \& Witter, G. P. (2010). Influência da família na decisão profissional: opinião de adolescentes. Psicologia Escolar e Educacional, 14(1), 15-22. Recuperado de http://www.scielo.br/pdf/ pee/v14n1/v14n1 a02.pdf. doi: 10.1590/S1413$\underline{85572010000100002}$

Noronha, A. P. P., Ambiel, R. A. M. (2006). Orientação profissional e vocacional: análise da produção científica. Psico-USF, 11 (1), 75-84. Recuperado de http://www.scielo.br/pdf/pusf/v1 ln 1/v1 ln1 a09.pdf. doi: $10.1590 /$ S1413-82712006000100009

Noronha, A. P. P., \& Ambiel, R. A. M. (2015). Level of differentiation of vocational interests profiles: comparative study by age and schooling in a Brazilian sample. Paidéia, 25(60), 49-56. Recuperado de http://www.scielo.br/pdf/paideia/v25n60/19824327-paideia-25-60-0049.pdf. doi: 10.1590/1982$\underline{43272560201507}$

Oliveira, I. D. (2000). Orientação profissional no contexto atual. In I. D. Oliveira (Org.), Construindo caminhos: Experiências e técnicas em orientação profissional (pp. 35-52). Recife: Ed. Universitária da UFPE.

Oliveira, M. D., \& Melo-Silva, L. L. (2010). Estudantes universitários: a influência das variáveis socioeconômicas e culturais na carreira. Psicologia Escolar e Educacional, 1 4(1), 23-34. Recuperado de http://www.scielo.br/pdf/pee/v14n1/v14n1 a03.pdf. doi: $\underline{10.1590 / \text { S1413-85572010000100003 }}$
Ribeiro, M. M. F., Leal, S. S., Diamantino, F. C., \& Bianchi, H. A. (2011). A opção pela medicina e os planos em relação ao futuro profissional de estudantes de uma faculdade pública Brasileira. Revista Brasileira de Educação Médica, 35(3), 405-41 1. Recuperado de http://www.scielo.br/pdf/rbem/v35n3/a15v35n3. pdf. doi: $10.1590 /$ s0100-55022011000300015

Richardson, R. J. (1999). Pesquisa social: métodos e técnicas (3a ed.). São Paulo: Atlas.

Sales, A. C. M., \& Chamon, E. M. Q. O. (2011). Escolha da carreira e processo de construção da identidade profissional docente. Educação em Revista, 27(3), 183-210. Recuperado de http://www.scielo.br/pdf/ edur/v27n3/v27n3a10.pdf. doi:10.1590/S010246982011000300010

Santos, L. M. M. (2005). O papel da família e dos pares na escolha profissional. Psicologia em Estudo, 10(1), 57-66. Recuperado de http://www.scielo.br/pdf/ pe/v10n1/v1 Onl a07.pdf. doi: 10.1590/S141373722005000100008

Savickas, M. L., Nota, L., Rossier, J., Dauwalder, J-P., Duarte, M. E., Guichard, J., ... Van Vianen, A. E. M. (2009). Life designing: A paradigm for career construction in the 21 st Century. Journal of Vocational Behavior, 75(3), 239-250. Recuperado de https://www.sciencedirect. $\mathrm{com} /$ science/article/pii/S000187910900058X. doi: 10.1016/i.jvb.2009.04.004

Silva, C. R. E. (2010). Orientação profissional, mentoring, coaching e counseling: Algumas singularidades e similaridades em práticas. Revista Brasileira de Orientação Profissional, 11 (2), 299-309. Recuperado de http://pepsic.bvsalud.org/pdf/rbop/v1 ln2/ v1 ln2a14.pdf

Silva, J. S. (2004). A influência dos meios de comunicação social na problemática da escolha profissional: o que isso suscita à Psicologia no campo da orientação vocacional/profissional?. Psicologia: Ciência e Profissão, 24(4), 60-67. Recuperado de http:// www.scielo.br/pdf/pcp/v24n4/v24n4a08.pdf. doi:10.1590/S1414-98932004000400008

Silva, S. S., Borges, L. O., \& Barbosa, S. C. (2014). A profissão de advogado conforme apresentada em jornais paraibanos. Psicologia \& Sociedade, 26(3), 652663. Recuperado de http://www.scielo.br/scielo. php?pid=S01 02-71822014000300014\&script=sci_ abstract\&tlng=pt. doi: $10.1590 / \mathrm{S0102}$ 71822014000300014

Soares, D. H. P. (2000). As diferentes abordagens em Orientação Profissional. In: M. L. Lisboa, \& D. H. P. Soares (Org.). A Orientação Profissional em ação: formação e prática de Orientadores Profissionais. São Paulo: Summus Editorial. 
Soares, D. H. P., Krawulski, E., Dias, M. S. L., \& D'Avila, G. T. (2007). Orientação profissional em contexto coletivo: uma experiência em pré-vestibular popular. Psicologia: Ciência e Profissão, 27(4), 746-759. Recuperado de http://www.scielo.br/pdf/pcp/ v27n4/v27n4a14.pdf. doi: 10.1590/S141498932007000400014

Super, D. E. (1973). The career development inventory. British Journal of Guidance \& Counselling, 1(2), 37 50. Recuperado de https://www.tandfonline.com/ doi/abs/10.1080/03069887308259350. doi: $10.1080 / 03069887308259350$

Super, D. E., \& Thompson, A. S. (1979). A six-scale, two factor measure of adolescent career vocational maturity. Vocational Guidance Quarterly, 28(1), 6-15. Recuperado de https://onlinelibrary.wiley.com/doi/ abs/10.1002/i.2164-585X.1979.tb00078.x. doi: 10.1002/i.2164-585X.1979.tb00078.x

Super, D. E., Savickas, M. L. \& Super, C. M. (1996). A abordagem vida-espaço, vida-espaço para carreiras. In D. Brown \& L. Brooks (Orgs.), Escolha de carreira e desenvolvimento (3a ed., pp. 121-178). San Fransisco: Jossey-Bass Publishers.

Tartuce, G. L. B. P., Nunes, M. M. R., \& Almeida, P. C. A. (2010). Alunos do ensino médio e atratividade da carreira docente no Brasil. Cadernos de Pesquisa, 40(1 40), 445-477. Recuperado de http://www.scielo. $\mathrm{br} / \mathrm{pdf} / \mathrm{cp} / \mathrm{v} 40 \mathrm{n} 140 / \mathrm{a} 0840140 . p d f$. doi: $10.1590 /$ S0100-15742010000200008

Uvaldo, M. C. C. \& Silva, F. F. (2010). Escola e escolha profissional: um olhar sobre a construção de projetos profissionais. In R. Levenfus, \& D. H. P. Soares (Orgs.), Orientação vocacional ocupacional (2a ed., pp. 31 38). Porto Alegre: Artmed.

Valore, L. A. (2010). Orientação profissional em grupo na escola pública: direções possíveis, desafios necessários. In R. Levenfus, \& D. H. P. Soares (Orgs.), Orientação vocacional ocupacional ( $2 a$ ed., pp. 65-81). Porto Alegre: Artmed.

Watson, M., \& Mcmahon, M. (2015). An introduction to career assessment. In M. McMahon, \& M. Watson (Eds.), Career assessment: qualitative approach (pp.3-11). Rottesdam: Sense.

Wright, J. T. C., Silva, A. T. B., \& Spers, R.G. (2010). O mercado de trabalho no futuro: uma discussão sobre profissões inovadoras, empreendedorismo e tendências para 2020. Revista de Administração e Inovação, 7(3), 174-197. Recuperado de https://www. revistas.usp.br/rai/article/viewFile/79186/83258. doi: $10.5585 /$ RAl. 2010.505 